\title{
Evaluation of a re-useable bronchoscopy biosimulator with ventilated lungs
}

\author{
Justin L. Garner ${ }^{1,2}$, Stefan D. Garner ${ }^{3}$, Robin J. Hardie ${ }^{1}$, Philip L. Molyneaux ${ }^{1,2}$, \\ Suveer Singh ${ }^{1,2}$, Samuel V. Kemp ${ }^{1}$ and Pallav L. Shah ${ }^{1,2}$
}

Affiliations: ${ }^{1}$ Royal Brompton Hospital, London, UK. ${ }^{2}$ National Heart and Lung Institute, Imperial College London, London, UK. ${ }^{3}$ Retired general practitioner, London, UK.

Correspondence: Justin L. Garner, Muscle Laboratory, Royal Brompton Hospital, Fulham Road, London, SW3 6HP, UK. E-mail: j.garner@rbht.nhs.uk

\section{ABSTRACT}

Background: Restrictions on respiratory trainee time and access to procedures reduce the opportunities to acquire necessary skills in bronchoscopy. Simulation, not subject to such impediments, is a useful supplementary aid to teaching bronchoscopic techniques in a safe environment but there is a limited choice of simulators that are sufficiently realistic and not prohibitively expensive. This study evaluated a low-cost device that simulates an intubated and ventilated patient, employing re-useable, inflatable, BioFlex-preserved, porcine lungs.

Methods: 26 bronchoscopists, trainee and experienced, after using the bronchoscopy biosimulator, completed a questionnaire using a five-point Likert scale comparing its performance with that of the computerised CAE AccuTouch.

Results: Participants were largely positive about their experience (mean score of 4.76). The bronchoscopy biosimulator was found to be realistic (mean score 4.64), easy to use (mean score 4.88), and helpful in learning to perform a variety of diagnostic and therapeutic procedures (mean score 4.85). Importantly, the bronchoscopy biosimulator compared favourably to the computer simulator (mean score 4.84).

Conclusions: These data support the concept of the bronchoscopy biosimulator as an acceptable model with which to supplement the experience of bronchoscopic procedures.

@ERSpublications

A re-useable bronchoscopy biosimulator with ventilated lungs hones skills in an environment that is realistic, is free of patient safety issues and time constraints, and provides a complementary training tool to commercially available simulation models http://ow.ly/AkWM30octSd

Cite this article as: Garner JL, Garner SD, Hardie RJ, et al. Evaluation of a re-useable bronchoscopy biosimulator with ventilated lungs. ERJ Open Res 2019; 5: 00035-2019 [https://doi.org/10.1183/ 23120541.00035-2019].

This article has supplementary material available from openres.ersjournals.com

Received: Feb 052019 | Accepted after revision: March 112019

Copyright $\odot$ ERS 2019. This article is open access and distributed under the terms of the Creative Commons Attribution Non-Commercial Licence 4.0. 


\section{Introduction}

Bronchoscopy is an invaluable procedure for many specialities, including anaesthesiology [1], intensive care $[2,3]$, respiratory medicine $[4]$ and thoracic surgery $[5,6]$. The learning curve for the acquisition of bronchoscopy skills, however, is steep and very individual [7].

A case should be made for mandatory teaching on a simulator for would-be bronchoscopists $[8,9]$. Employment of trainees in the operating room has been shown to add to the duration of the procedure by an average of $18 \mathrm{~min}$ with a potential for up to three-fold increased risk of complications for the patient [10]. Moreover, as much as a five-fold increase in the costs of repairs to bronchoscopes has been reported [11]. With an average of 3.5 weeks for repairs [12], this has serious implications for a bronchoscopy service. This has been addressed with an education programme employing a simulator [13].

Simulation has been shown to improve trainees' performance in the operating room [14-17]. A systematic review of 30 publications on flexible bronchoscopy and endobronchial ultrasound showed simulation-based training to be more efficient than the traditional apprenticeship model for trainees at the start of their career, and advised this should be compulsory [18]. Furthermore, a training programme incorporating self-directed learning and using a combination of physical and virtual reality simulators was recommended [18].

There are a number of simulators currently available that are reported to deliver anatomically authentic reconstructions of the airway tree [19] but lack realistic tactile feedback of respiration and instrument/ airway interaction [8]. Expense tends to restrict the higher fidelity models to central teaching hospitals [8].

We have developed a low-cost, easy-to-use bronchoscopy biosimulator utilising re-useable, inflatable, BioFlex-preserved porcine lungs. The objective of this study was to evaluate its acceptability as a training aid for diagnostic procedures (inspection, endobronchial brush and biopsy) and for therapeutic interventions (foreign body retrieval and endobronchial valve implantation) in the lower airways, and facilitate more widespread availability.

\section{Materials and methods}

The device

The bronchoscopy biosimulator was conceived by J.L. Garner, and developed in collaboration with S.D. Garner and R.J. Hardie. BioQuest porcine lungs (Medisave UK Ltd, Weymouth, UK) housed hygienically in a clear acrylic box, supported if necessary, for smaller lungs by a removable platform, were connected to a bulkhead coupling (a tube passing through the front of the box). Hand-operated bellows were linked to the coupling via a conventional double-swivel elbow connector with bronchoscopy port and a shortened, size 9.0, uncuffed endotracheal tube that was push-fitted into the external, chamfered orifice of the coupling to create a closed ventilator system (figure 1).

When not in use, the lungs were stored in a sandwich box (dimensions $220 \times 160 \times 80 \mathrm{~mm}$ ), immersed in BioFlex solution, a patented humectant fluid (25\% propylene glycol and $75 \%$ water) that prevents tissue desiccation, inhibits bacterial growth, is nontoxic and is biodegradable. The box and fittings, which can be dismantled if necessary, were cleaned with Clinell Universal Wipes (GAMA Healthcare, Watford, UK).

\section{The simulation session}

Two groups of bronchoscopists, experienced $(n=11)$ and trainee $(n=15)$, were invited to attend a simulation session using the bronchoscopy biosimulator and the AccuTouch bronchoscopy simulator by

FIGURE 1 The bronchoscopy biosimulator and Ambu aScope 4 Broncho Large connected to aView monitor.

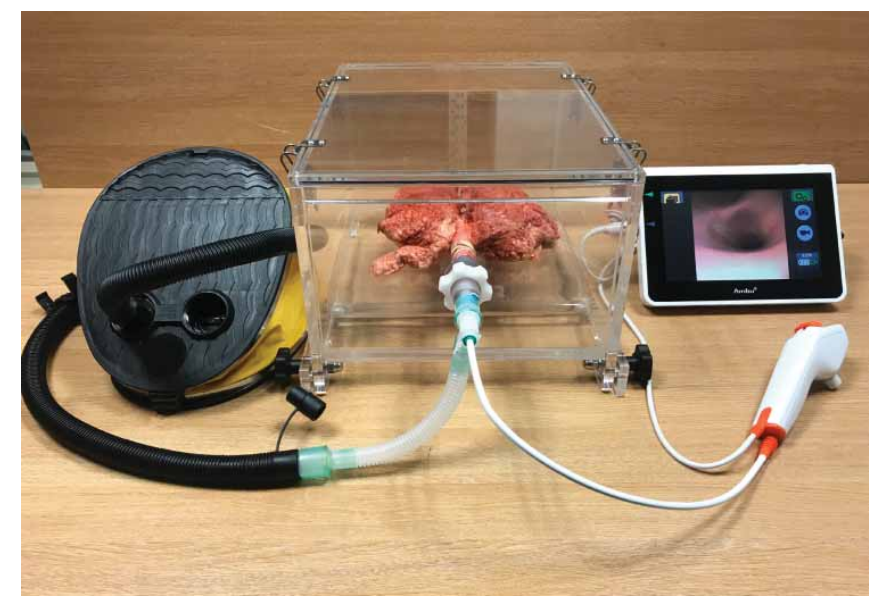


PORCINE AIRWAY MODEL QUESTIONNAIRE

Thank you for taking the time to complete this questionnaire. Your feecback is valuable in helpin to create more realistic simulation environments for future course attendees and trainee maximising patient safe

Please tick the most applicable response for vou using the 5-point likert scale.

Item 1: The porcine airway model is helpful in learning how to perform:

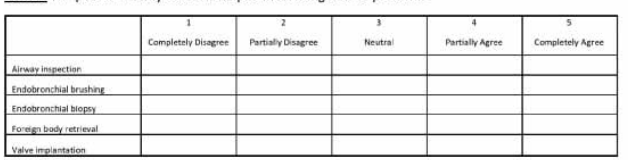

Item 2: The porcine airway model is helpful to learn how to interact with an assistant while performing

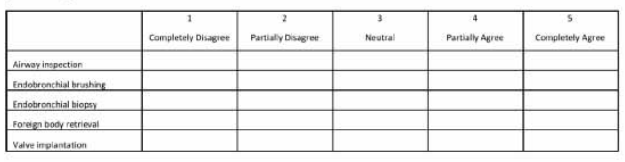

Item 3: The porcine airway model is helpful to demonstrate safety issues associated with:

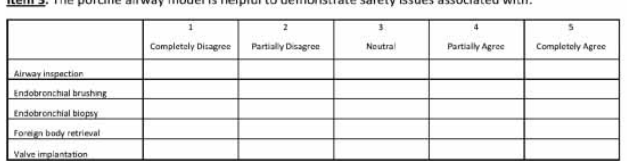

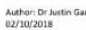

Item 4: The porcine airway model compares favourably with the computer simulator for learning Item 4: The por
how to pertorm:

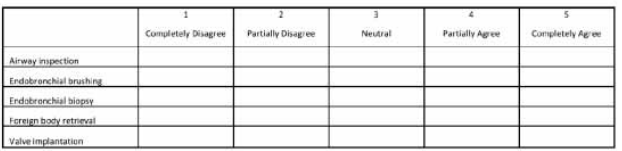

Item 5: After this experience, I feel more confident performing:

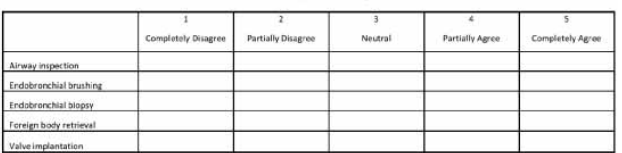

tem 6: Based on my past experiences with bronchoscopy, the porcine airway model is realistic

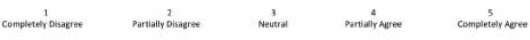

Item 7: The porcine airway model is easy to use:

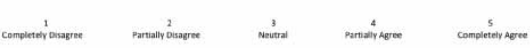

comments

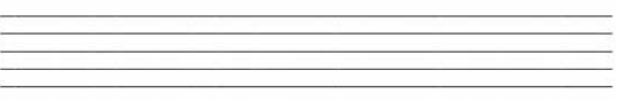

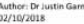

FIGURE 2 Questionnaire using a seven-item, five-point Likert scale to evaluate the bronchoscopy biosimulator

CAE Healthcare (Oxford, UK). Experienced bronchoscopists were defined as those with $\geqslant 4$ years of procedural exposure and trainee bronchoscopists as those with $\leqslant 1$ year of exposure.

Inspection of the airways, endobronchial brushing and endobronchial biopsy were practised on both devices. Foreign body retrieval and endobronchial valve implantation, not options on our AccuTouch, were also performed on the bronchoscopy biosimulator.

\section{The evaluation}

Attendees were asked to complete a questionnaire reflecting their opinions on the capabilities and realism of both simulators using a seven-item, five-point Likert scale (figure 2) adapted from that used by GoldBerg et al. [20]. As this was used as a service evaluation tool, no ethical approval was required.

\section{Statistical analysis}

Data are presented as median (interquartile range) and mean \pm sD. Comparisons between experienced and trainee groups were evaluated using the Mann-Whitney U-test. Statistical analysis was performed using SPSS version 24.0 (IBM, Chicago, IL, USA). Differences were considered to be statistically significant when the p-value was $<0.05$.

\section{Results}

26 bronchoscopists, 11 experienced and 15 trainees, took part in this service evaluation. Both groups were positive about their simulation encounter (mean score of 4.76) (figures 3 and 4 and tables S1 and S2). The bronchoscopy biosimulator was found to be helpful in learning to perform a variety of diagnostic and therapeutic procedures (mean score of 4.85), interacting with an assistant (mean score of 4.85) and demonstration of safety issues (mean score of 4.70). Importantly, the bronchoscopy biosimulator compared favourably to the computer simulator (mean score of 4.84), improved operator confidence (mean score of 4.47), was realistic (mean score of 4.64) and easy to use (mean score of 4.88).

Statistically significant differences were observed between experienced and trainee bronchoscopists, respectively, in their feedback on: 1) assistant interaction when performing airway inspection (mean scores of 4.55 versus $4.87 ; \mathrm{p}=0.037$ ) and valve implantation (mean scores of 4.60 versus $4.93 ; \mathrm{p}=0.046$ ); 2 ) safety when performing airway inspection (mean scores of 4.45 versus $4.87 ; \mathrm{p}=0.034$ ) and foreign body retrieval (mean scores of 4.45 versus $4.87 ; \mathrm{p}=0.034$ ); and 3 ) confidence in performing airway inspection (mean scores of 3.82 versus 4.87; $\mathrm{p}=0.005$ ) and endobronchial brushing (mean scores of 4.00 versus 4.86; $\mathrm{p}=0.024)$. 
a)

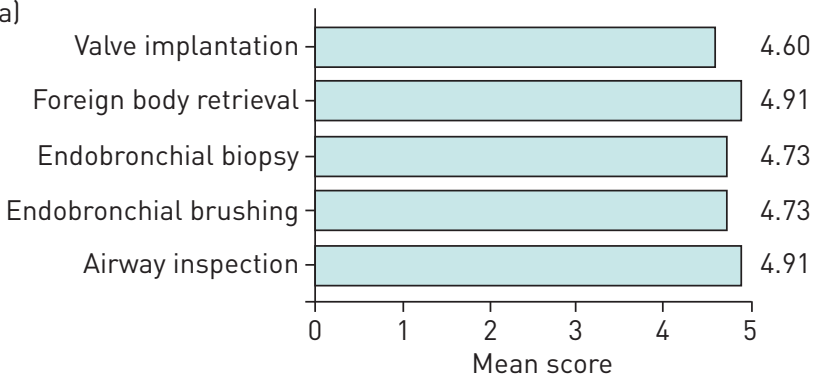

c)

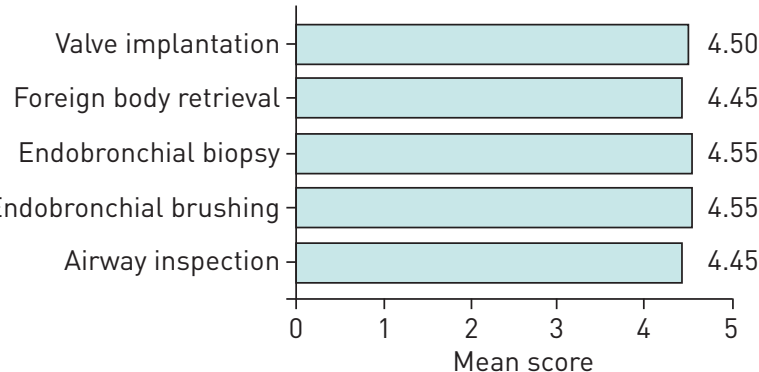

e)

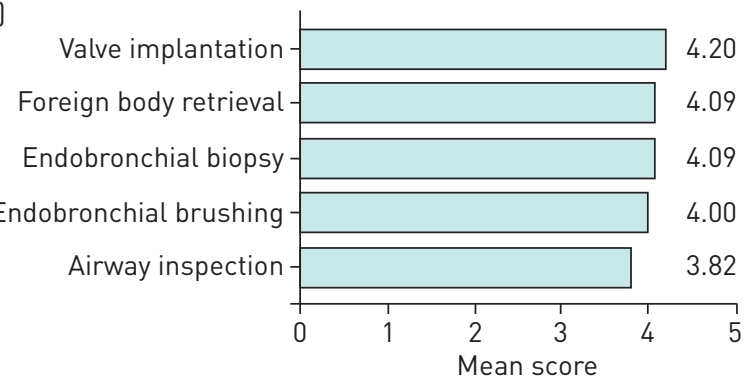

b)

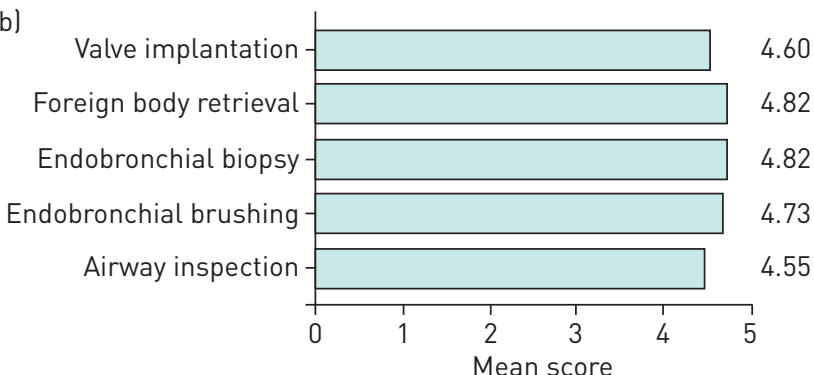

d)

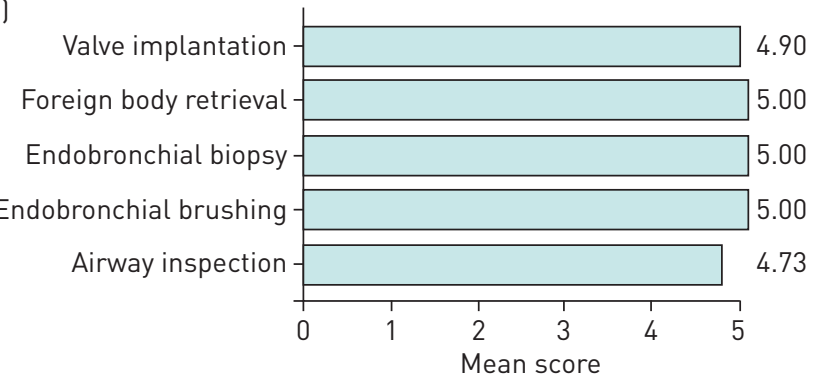

f)

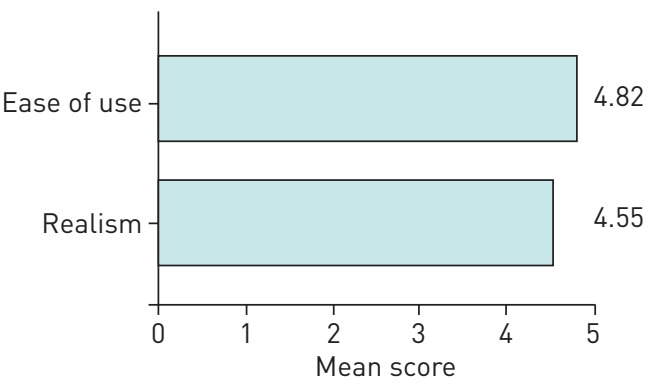

FIGURE 3 Experienced bronchoscopists' feedback. a) Item 1: learning how to perform. b) Item 2: interaction with assistant. c) Item 3: demonstration of safety issues. d) Item 4: comparison to AccuTouch. e) Item 5: confidence. f) Items 6 and 7: realism and ease of use.

\section{Discussion}

Although an established aid, choice of bronchoscopic simulators is limited. Realism and cost are issues [8]: the bronchoscopy biosimulator addresses these problems. The model employs a hand-ventilated porcine lung to represent an intubated and ventilated patient. The bronchial anatomy is of course not identical to that of the human lung and it is not intended for teaching this aspect [21]. However, the appearance of the airways, the elasticity of the lung, and its responses to inflation and deflation are, to judge from experienced feedback, indistinguishable. The tactile feedback is unmatched by synthetic simulators.

The porcine lungs preserved in BioFlex solution are obtained from BioQuest, who also supply the bellows, and advice on maintenance and storage. It has proven robust in use for up to 12 months. Air leaks, after biopsy, can be managed with prolene suture or staple. Irreparably damaged lungs are easily replaced at a low cost of approximately GBP 88 (USD 115).

The bronchoscopy biosimulator is compact, lightweight and portable, and is quickly and easily set up. The orientation of its mount is adjustable. Cleaning and storage, as instructed, are simple, but important to ensure its reusability. In use, the lungs are in a sealed container and the ventilation system is closed: aerosolisation is unlikely.

A bronchoscope dedicated for use only with this simulator is recommended. The aScope 4 (Ambu, Copenhagen, Denmark) series of bronchoscope with its monitor is inexpensive [22], produces good imaging, is robust [23] and is, for this purpose, re-usable.

Our results show that trainee and established bronchoscopists find the bronchoscopy biosimulator beneficial for learning diagnostic and therapeutic procedures in the lower airways, improves operator confidence and assistant interaction, is realistic, and is easy to use.

The cost estimated to build the bronchoscopy biosimulator is GBP 1500 (USD 1970). Low-fidelity products, for example, Nakhosteen's Broncho Boy and AirSim Bronchi (TruCorp Ltd, Belfast, UK) are 
a)

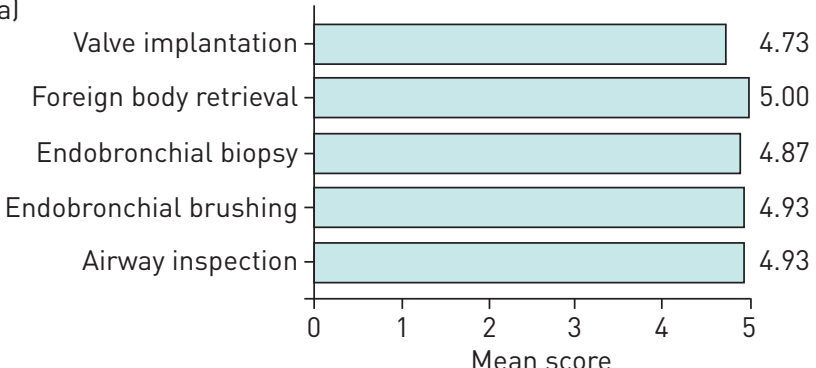

c)

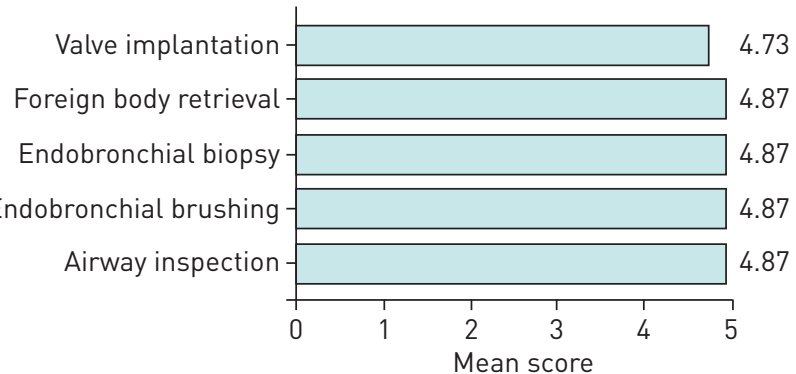

e)

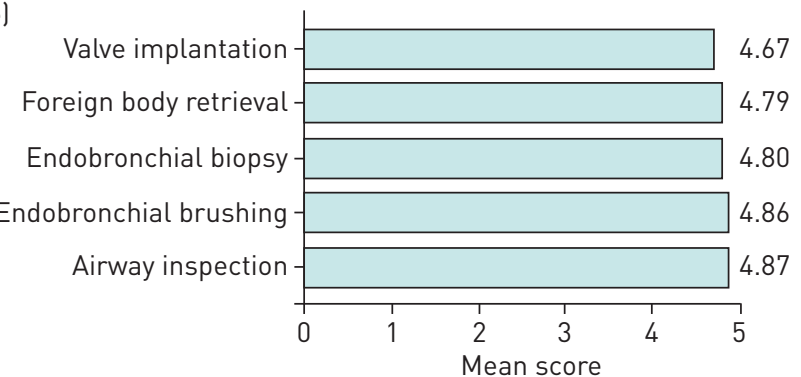

b)

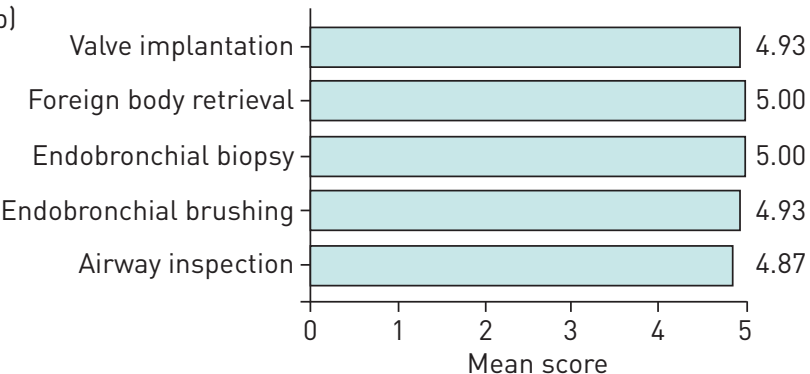

d)

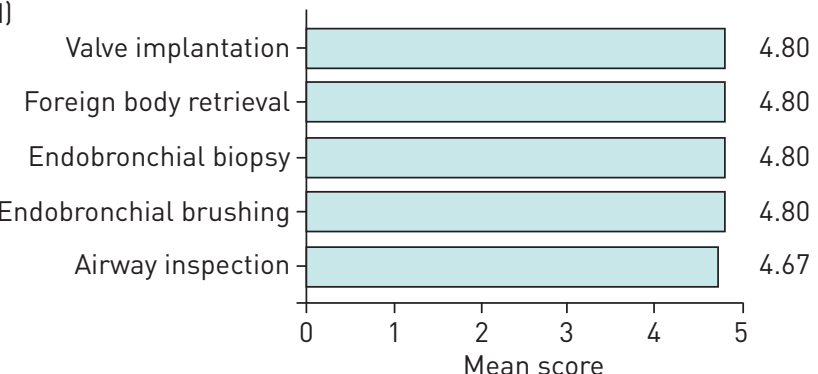

f)

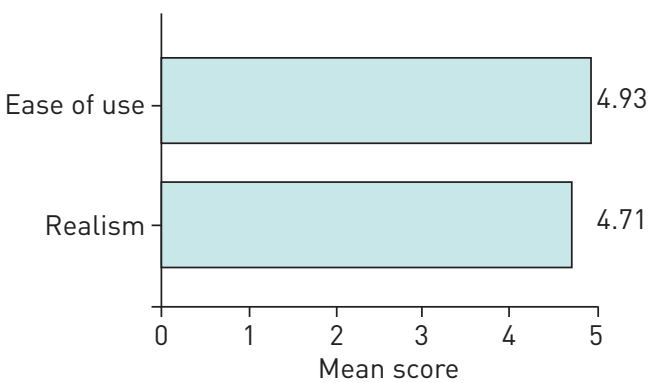

FIGURE 4 Trainee bronchoscopists' feedback. a) Item 1: learning how to perform. b) Item 2: interaction with assistant. c) Item 3: demonstration of safety issues. d) Item 4: comparison to AccuTouch. e) Item 5: confidence. f) Items 6 and 7: realism and ease of use.

marketed at GBP 3073 (USD 4033) and GBP 3551 (USD 4660), respectively; CAE EndoVR (successor to the AccuTouch) is GBP 80000 and other high-fidelity simulators cost approximately GBP 33000-80000.

\section{Conclusions}

Bronchoscopy is a valued tool that is increasingly in demand for the assessment and treatment of respiratory disorders. However, its safe and effective deployment demands a high degree of skill in its operators, acquired through experience and practice.

The bronchoscopy biosimulator, a supplement to patient contact, contributes to the opportunities to develop skills in an environment that is realistic, is free of patient safety issues and time constraints, and provides a complementary training tool to commercially available simulation models.

Acknowledgements: Special thanks to Ines Meireles, Cielito Caneja, Eric D. Tenda, Karthi Srikanthan, Christopher M. Orton, Arafa M. Aboelhassan, Lydia J. Finney, Dexter Wiseman, Michael R. Loebinger and Nicholas S. Hopkinson (Royal Brompton Hospital, London, UK), who tested the bronchoscopy biosimulator and provided constructive feedback, and to Siobhan Crichton (statistician for the MRC Clinical Trials Unit at UCL, London, UK) who reviewed the data analysis.

Author contributions: J.L. Garner is the guarantor of the content of the manuscript, including the data and analysis J.L. Garner wrote the first draft of the manuscript and made revisions after feedback from co-authors. J.L. Garner, S.D. Garner and R.J. Hardie contributed to the design and manufacture of the biosimulator. S.D. Garner, R.J. Hardie, P.L. Molyneaux, S. Singh, S.V. Kemp and P.L. Shah tested the Bronchoscopy BioSim, contributed to data analysis and interpretation, and made significant contributions to the manuscript. All the authors meet the definition of an author as stated by the International Committee of Medical Journal Editors, and all have seen and approved the final manuscript.

Conflict of interest: J.L. Garner has nothing to disclose. S.D. Garner has nothing to disclose. R.J. Hardie has nothing to disclose. P.L. Molyneaux has nothing to disclose. S. Singh has nothing to disclose. S.V. Kemp reports that he was a principal investigator on a commercial valve study for, his institution was reimbursed for clinical trial expenses for the TRANSFORM trial by and he has received lecture fees from PulmonX, his institution was reimbursed for clinical trial expenses by PneumRx, and he has received consultancy fees from Boston Scientific, outside the submitted work. P.L. Shah reports personal fees from Boston Scientific, Broncus, CSA Medical, Creo Medical, Nuvairia Olympus, 
Medtronic and PneumRX/BTG as consultant on scientific advisory boards, and sponsorship to Imperial College for a bronchoscopy course by from ERBE, Cook Medical, Medtronic, Boston Scientific, Broncus, Pulmonx, Olympus and PneumRX/BTG, outside the submitted work. He has been an investigator on clinical trials with endobronchial valves, endobronchial coils, thermal ablation and the airway bypass procedure.

\section{References}

Ovassapian A. The flexible bronchoscope. A tool for anesthesiologists. Clin Chest Med 2001; 22: 281-299.

Kabadayi S, Bellamy MC. Bronchoscopy in critical care. BJA Educ 2017; 17: 48-56.

Ergan B, Nava S. The use of bronchoscopy in critically ill patients: considerations and complications. Expert Rev Respir Med 2018; 12: 651-663.

4 Miller RJ, Casal RF, Lazarus DR, et al. Flexible bronchoscopy. Clin Chest Med 2018; 39: 1-16.

5 Jackson C, Tucker G, Clerf LH, et al. Bronchoscopy as an aid to the thoracic surgeon. JAMA 1925; 84: 97-103.

6 Chhajed PN, Eberhardt R, Dienemann H, et al. Therapeutic bronchoscopy interventions before surgical resection of lung cancer. Ann Thorac Surg 2006; 81: 1839-1843.

7 Wahidi MM, Silvestri GA, Coakley RD, et al. A prospective multicenter study of competency metrics and educational interventions in the learning of bronchoscopy among new pulmonary fellows. Chest 2010; 137: $1040-1049$.

8 Ernst A, Wahidi MM, Read CA, et al. Adult bronchoscopy training: current state and suggestions for the future: CHEST expert panel report. Chest 2015; 148: 321-332.

9 Du Rand IA, Barber PV, Goldring J, et al. Summary of the British Thoracic Society guidelines for advanced diagnostic and therapeutic flexible bronchoscopy in adults. Thorax 2011; 66: 1014-1015.

10 Stather DR, MacEachern P, Chee A, et al. Trainee impact on procedural complications: an analysis of 967 consecutive flexible bronchoscopy procedures in an interventional pulmonology practice. Respiration 2013; 85 $422-428$.

11 McCahon RA, Whynes DK. Cost comparison of re-usable and single-use fibrescopes in a large English teaching hospital. Anaesthesia 2015; 70: 699-706.

12 Kirkpatrick MB, Smith JR, Hoffman PJ, et al. Bronchoscope damage and repair costs: results of a regional postal survey. Respir Care 1992; 37: 1256-1259.

13 Lunn W, Garland R, Gryniuk L, et al. Reducing maintenance and repair costs in an interventional pulmonology program. Chest 2005; 127: 1382-1387.

14 Ost D, DeRosiers A, Britt EJ, et al. Assessment of a bronchoscopy simulator. Am J Respir Crit Care Med 2001; 164: 2248-2255.

15 Blum MG, Powers TW, Sundaresan S. Bronchoscopy simulator effectively prepares junior residents to competently perform basic clinical bronchoscopy. Ann Thorac Surg 2004; 78: 287-291.

16 Kennedy CC, Maldonado F, Cook DA. Simulation-based bronchoscopy training: systematic review and meta-analysis. Chest 2013; 144: 183-192.

17 Nilsson PM, Naur TMH, Clementsen PF, et al. Simulation in bronchoscopy: current and future perspectives. $A d v$ Med Educ Pract 2017; 8: 755-760.

18 Naur TMH, Nilsson PM, Pietersen PI, et al. Simulation-based training in flexible bronchoscopy and endobronchial ultrasound-guided transbronchial needle aspiration (EBUS-TBNA): a systematic review. Respiration 2017; 93: 355-362.

19 Colt HG. Simulation in bronchoscopy training: are we there yet? Curr Respir Care Rep 2013; 2: 61-68.

20 Goldberg R, Colt HG, Davoudi M, et al. Realistic and affordable lo-fidelity model for learning bronchoscopic transbronchial needle aspiration. Surg Endosc 2009; 23: 2047-2052.

21 Judge EP, Hughes JM, Egan JJ, et al. Anatomy and bronchoscopy of the porcine lung. A model for translational respiratory medicine. Am J Respir Cell Mol Biol 2014; 51: 334-343.

22 Perbet S, Blanquet M, Mourgues C, et al. Cost analysis of single-use (Ambu ${ }^{\circ}$ aScope) and reusable bronchoscopes in the ICU. Ann Intensive Care 2017; 7: 3.

23 Vijayakumar M, Clarke A, Wilkes AR, et al. Comparison of the manoeuvrability and ease of use of the Ambu aScope and Olympus re-usable fibrescope in a manikin. Anaesthesia 2011; 66: 689-693. 